Proceeding

\title{
Gas Detection Using LMR-Based Optical Fiber Sensors ${ }^{\dagger}$
}

\author{
Uilian José Dreyer 1, Aritz Ozcariz 2, Joaquín Ascorbe 2, Pablo Zubiate ${ }^{2}$, Ignacio Vitoria ${ }^{2}$, \\ Cicero Martelli ${ }^{1}$, Jean Carlos Cardozo da Silva ${ }^{1}$ and Carlos Ruiz Zamarreño ${ }^{2,3}$,* \\ 1 Graduate Program in Electrical and Computer Engineering, UTFPR-Paraná, Curitiba 80230-901, Brazil; \\ uiliandreyer@utfpr.edu.br (U.J.D.); cmartelli@utfpr.edu.br (C.M.); jeanccs@utfpr.edu.br (J.C.C.d.S.) \\ 2 Electrical and Electronic Engineering Department, UPNA, Campus Arrosadia, 31006 Pamplona, Spain; \\ aritz.ozcariz@unavarra.es (A.O.); joaquin.ascorbe@unavarra.es (J.A.); pablo.zubiate@unavarra.es (P.Z.); \\ ignacio.vitoria@unavarra.es (I.V.) \\ 3 Institute of Smart Cities, Jerónimo de Ayanz, 31006 Pamplona, Spain \\ * Correspondence: carlos.ruiz@unavarra.es; Tel.: +34-948-168445 \\ † Presented at the Eurosensors 2018 Conference, Graz, Austria, 9-12 September 2018.
}

Published: 21 November 2018

\begin{abstract}
This work presents a first approach to the utilization of Lossy Mode Resonance (LMR) based optical fiber sensors for gas detection. The optical sensor is based on a $\mathrm{SnO}_{2}$ thin-film fabricated onto the core of cladding removed multimode fibers (MMF). The time response of the device to four different gases $\left(\mathrm{NH}_{3}, \mathrm{NO}, \mathrm{CO}_{2}\right.$ and $\left.\mathrm{O}_{2}\right)$ was monitored obtaining the best sensitivity for $\mathrm{NO}$ whereas the response to $\mathrm{NH}_{3}$ revealed the best repeatability.
\end{abstract}

Keywords: gas sensing; Lossy Mode Resonance; optical fiber sensors

\section{Introduction}

Gas detection is an important issue in industrial environments and it is mainly associated to the risks involved in accidents. Therefore, it is required the utilization of reliable, accurate and fast gas detection systems [1]. Optical fiber sensors can overcome conventional methods in several features, such as electromagnetic immunity, easy multiplexing, low losses and intrinsically safe detection (not carrying electricity). In particular, optical fiber LMR-based sensors comprising a thin metal oxide film, such as $\mathrm{SnO}_{2}$, have been presented as a high sensitive and versatile tool [2]. Ample documentation can be found in literature regarding the utilization of metal oxides and $\mathrm{SnO}_{2}$ thin films in gas sensing applications [3]. On the other hand, it had never been explored before by means of the utilization of LMR-based optical fiber sensors.

\section{Materials and Methods}

This work presents a first approach to measure the response of LMR-based sensors to different gases, such as $\mathrm{NH}_{3}(1890 \mathrm{ppm}), \mathrm{NO}(301 \mathrm{ppb}), \mathrm{CO}_{2}$ (pure) and $\mathrm{O}_{2}$ (pure), generally present in industrial processes. All the experiments used $\mathrm{N}_{2}$ with $99.99 \%$ purity as the reference level for detection. The experimental transmission setup is represented in Figure 1a with the sensitive region introduced in a stainless steel gas cell. The sensitive region consisted of a MMF with $200 \mu \mathrm{m}$ core diameter and 2 cm long. $200 \mathrm{~nm}$ thick $\mathrm{SnO}_{2}$ films were fabricated onto the MMF core by means of DC sputtering technique [4]. A prior characterization of the device was performed with the sensitive region immersed in glycerin/water concentrations ranging from 0 to $80 \%$ (see Figure $1 \mathrm{~b}$ ). The resonance of the device shifts to longer wavelengths as a function of the external refractive index (RI). The sensitivity, $1106 \mathrm{~nm} / \mathrm{RIU}$, could be easily improved by means of the utilization of a more complex 
setup comprising D-shape fibers as well as first order resonances [5-6] but this is not the objective of this study. The response of the device to the gases was performed during 5 cycles of 5 min in $\mathrm{N}_{2}$ and $5 \mathrm{~min}$ in the gas under study. The nitrogen gas flow is set to $0.5 \mathrm{~L} / \mathrm{min}$ while the gases under test is $0.25 \mathrm{~L} / \mathrm{min}$.
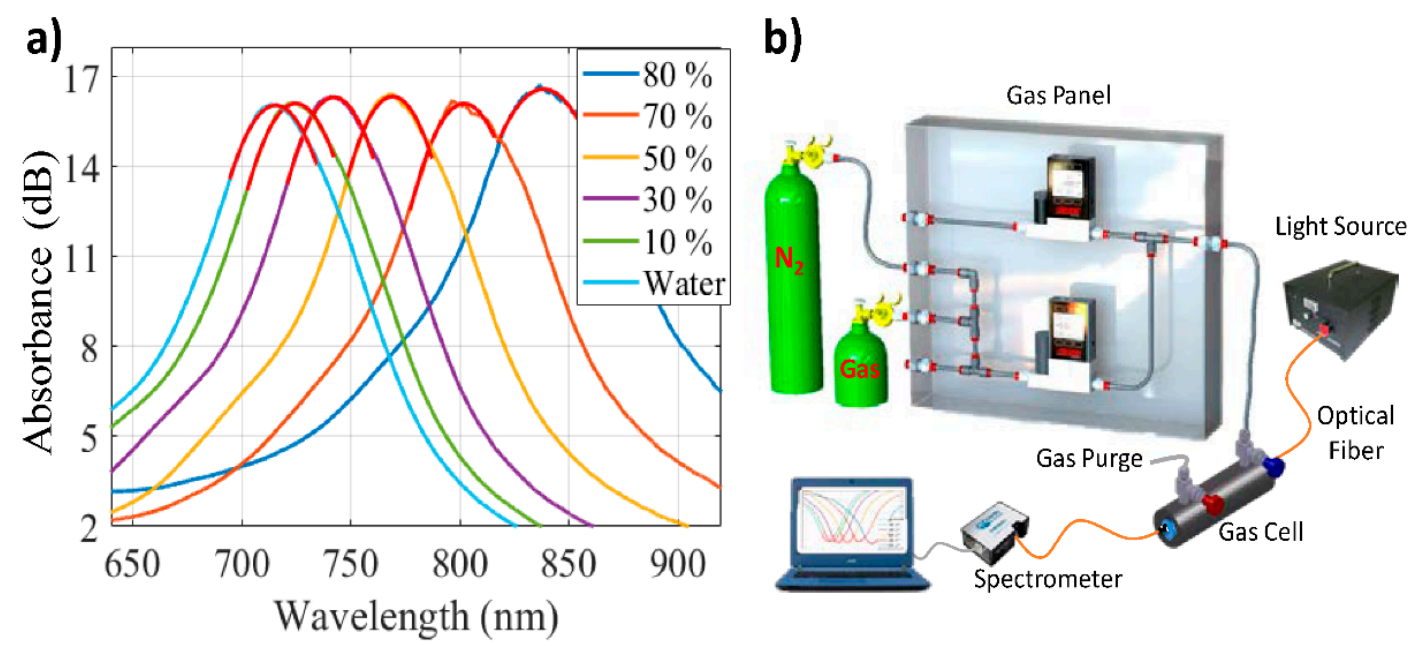

Figure 1. (a) Spectral response of the LMR refractometer when the sensitive region is immersed in different water/glycerin solutions at different concentrations $(80 \%=1.443 \mathrm{RIU}, 70 \%=1.428 \mathrm{RIU}, 50 \%$ $=1.398 \mathrm{RIU}, 30 \%=1.370 \mathrm{RIU}, 10 \%=1.345 \mathrm{RIU}, 0 \%=1.333 \mathrm{RIU}) ;(\mathbf{b})$ Experimental setup used to monitor the sensitivity of the device to different gases that consisted of a gas cell with an optical fiber pass-through for fiber connections to the optical source and detector as well as gas inlet and outlet.

\section{Results and Discussions}

The response of the fabricated devices (see Section 2) was tested under different gases. At the first five minutes of every gas test there is a resonance wavelength shift to shorter wavelengths as it can be observed in Figure 2. This can be attributed to the stabilization time of the temperature and humidity conditions in the gas chamber at the first stage after closure compared to the natural air conditions present during the gas cell assembly. If we omit this first cycle we can observe a LMR wavelength shift of $4.5 \mathrm{~nm}, 1.5 \mathrm{~nm}, 3 \mathrm{~nm}$ and $2 \mathrm{~nm}$ for the $\mathrm{NH}_{3}, \mathrm{NO}, \mathrm{CO}_{2}$ and $\mathrm{O}_{2}$ respectively with a mean response time smaller than $40 \mathrm{~s}$. The mean time response obtained with the presented sensor is in the same range of others optical gas sensors using different sensing technology [7-9]. The highest sensitivity was obtained with $\mathrm{NO}(5 \mathrm{pm} / \mathrm{ppb})$ while $\mathrm{NH}_{3}$ shown a highly repetitive response as well as a sensitivity of $2.4 \mathrm{pm} / \mathrm{ppm}$.

One of the most noteworthy characteristics of gas sensors is the response time. Hence, Figure 3 presents a closer view of the results from the Figure 2 for each gas under test. The response time is the rise time measured from $10 \%$ to $90 \%$ of the resonance wavelength shift. As well as the highest sensitivity NO revealed the fastest response time response, about $10 \mathrm{~s}$ (see Figure 3b). It is also important to note that the shortest response time is associated to the smallest resonance wavelength shift while the longer response times correspond to the larger resonance wavelength shifts. However, a more detailed study of this behavior should be performed in order to stablish a clear relationship between response time and resonance wavelength shift with different gases and at different concentrations. 


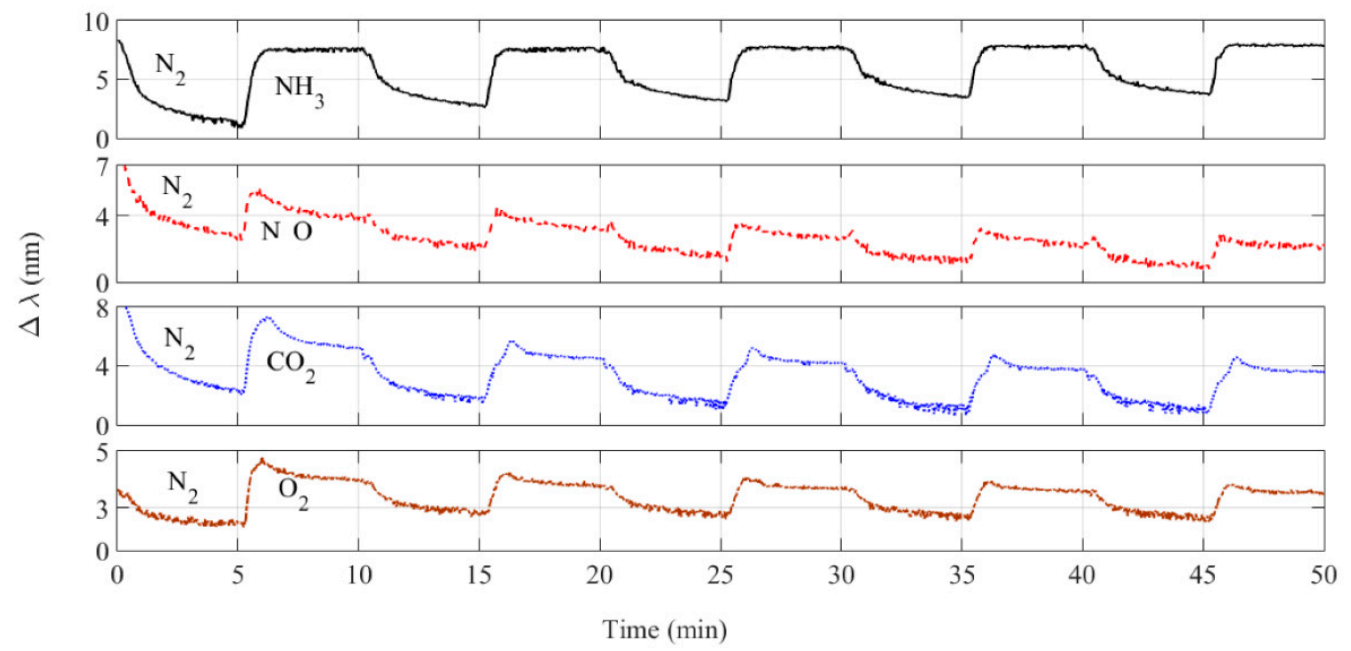

Figure 2. LMR wavelength shift when the sensitive region of the device is exposed to different concentrations of $\mathrm{NH}_{3}\left(1890 \mathrm{ppm}\right.$ ), $\mathrm{NO}$ (301 ppb), $\mathrm{CO}_{2}$ (pure) and $\mathrm{O}_{2}$ (pure) for cycles of $5 \mathrm{~min}$ followed by $5 \mathrm{~min}$ of recovery time in $\mathrm{N}_{2}$.
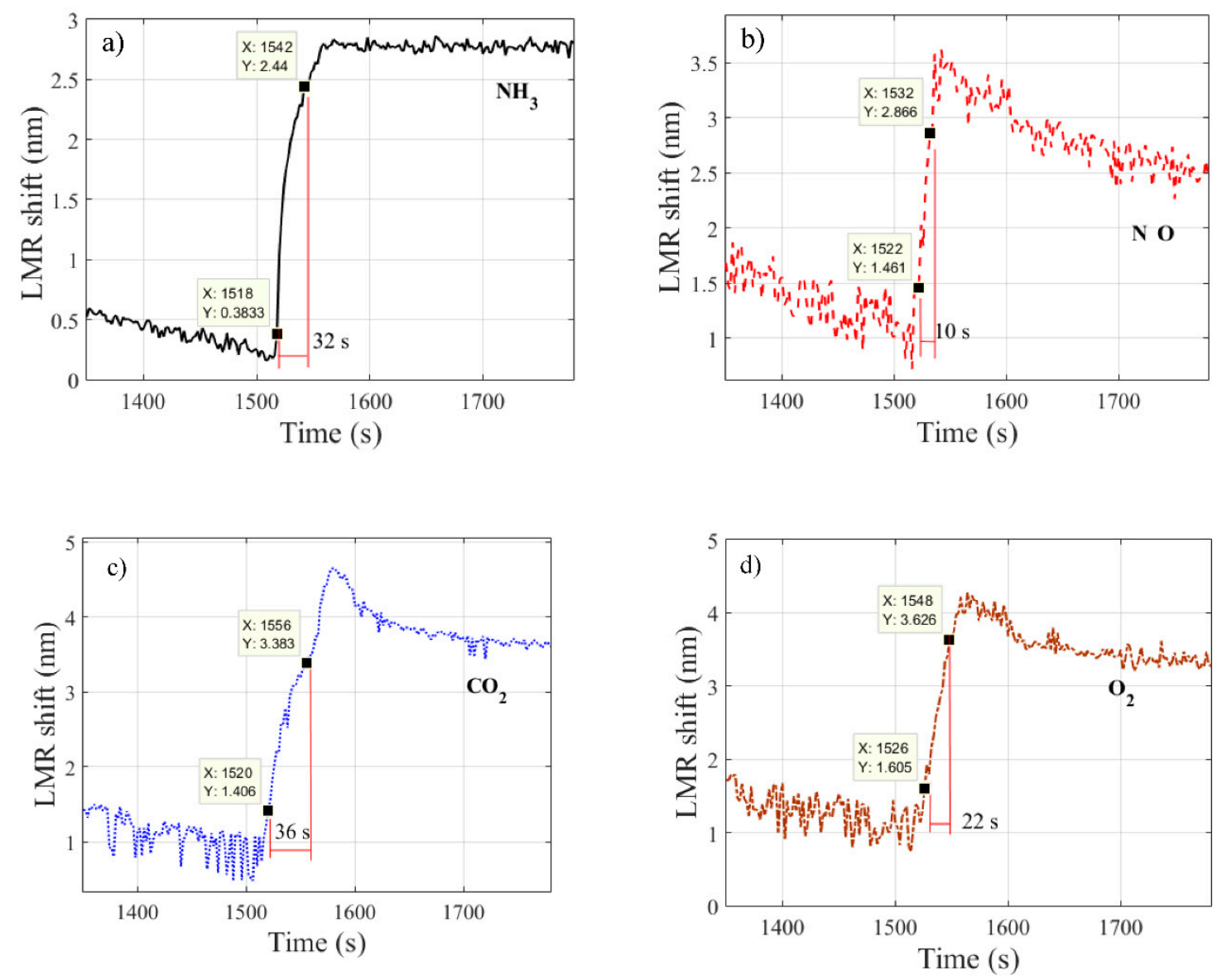

Figure 3. Time response of the LMR optical sensor during the third gas under test cycle: (a) $\mathrm{NH}_{3}$, (b) $\mathrm{NO},(\mathbf{c}) \mathrm{CO}_{2}$ and (d) $\mathrm{O}_{2}$.

\section{Conclusions}

This work presented a novel way to use the LMR sensors as a gas sensing tool. Results for refractive index response and gas sensing have been shown for the devices fabricated with $\mathrm{SnO}_{2}$ thin film. In particular, gas sensing test that consisted of five cycles alternating between the gas under test and pure nitrogen have been performed using four different gases: NH3 (1890 ppm), NO (301 ppb), 
$\mathrm{CO}_{2}$ (pure) and $\mathrm{O}_{2}$ (pure). The tests. The shortest response time as well as the highest sensitivity are $10 \mathrm{~s}$ and $5 \mathrm{pm} / \mathrm{ppb}$ respectively and where obtained with NO gas. Finally, it is important to remark that all the gases produced a response in the sensor by means of resonance wavelength shift, which reveals the potential of the utilization of these devices in gas sensing applications as well as the necessity to perform further studies on the optimal characteristics of the film and temperature operation to obtain selective responses with different gaseous species.

Author Contributions: C.R.Z. and U.J.D., conceived and designed the experiments; U.J.D., A.O., J.A. and P.Z. performed the experiments; C.M. and J.C.C.d.S. analyzed the data; I.V. and C.R.Z. contributed reagents/materials/analysis tools; U.J.D. and C.R.Z. wrote the paper.

Acknowledgments: The authors acknowledge the financial support of Fundação Araucária, Secretaria de Estado da Ciência, Tecnologia e Ensino Superior do Paraná (SETI), CNPq, CAPES, FINEP, ANEEL and Spanish Ministry of Economy and Competitiveness Research GrantTEC2016-78047-R.

Conflicts of Interest: The authors declare no conflict of interest and the founding sponsors had no role in the design of the study; in the collection, analyses, or interpretation of data; in the writing of the manuscript, and in the decision to publish the results.

\section{References}

1. Liu, X.; Cheng, S.; Liu, H.; Hu, S.; Zhang, D.; Ning, H. A Survey on Gas Sensing Technology. Sensors 2012, 12, 9635-9665.

2. Del Villar, I.; Arregui, F.J.; Zamarreño, C.R.; Corres, J.M.; Bariain, C.; Goicoechea, J.; Elosua, C.; Hernaez, M.; Rivero, P.J.; Socorro, A.B.; et al. Optical sensors based on lossy-mode resonances. Sens. Actuators B Chem. 2017, 240, 174-185.

3. Das, S.; Jayaraman, V. SnO2: A comprehensive review on structures and gas sensors. Prog. Mater. Sci. 2014, $66,112-255$.

4. Sanchez, P.; Zamarreño, C.R.; Hernaez, M.; Matias, I.R.; Arregui, F.J. Optical fiber refractometers based on Lossy Mode Resonances by means of $\mathrm{SnO}_{2}$ sputtered coatings. Sens. Actuators B Chem. 2014, 202, 154-159.

5. Arregui, F.J.; del Villar, I.; Zamarreño, C.R.; Zubiate, P.; Matias, I.R. Giant sensitivity of optical fiber sensors by means of lossy mode resonance. Sens. Actuators B Chem. 2016, 232, 660-665.

6. Ozcariz, A.; Zamarreño, C.R.; Zubiate, P.; Arregui, F.J. Is there a frontier in sensitivity with Lossy mode resonance (LMR) based refractometers? Sci. Rep. 2017, 7, 10280.

7. Preiß, E.M.; Rogge, T.; Krauß, A.; Seidel, H. Gas Sensing by $\mathrm{SnO}_{2}$ Thin Films Prepared by Large- area Pulsed Laser Deposition. Procedia Eng. 2015, 120, 88-91.

8. Cao, W.; Duan, Y. Optical fiber-based evanescent ammonia sensor. Sens. Actuators B Chem. 2005, 110, 252-259.

9. Huang, Y.; Wieck, L.; Tao, S. Development and evaluation of optical fiber $\mathrm{NH}_{3}$ sensors for application in air quality monitoring. Atmos. Environ. 2013, 66, 1-7.

(c) 2018 by the authors. Licensee MDPI, Basel, Switzerland. This article is an open access article distributed under the terms and conditions of the Creative Commons Attribution (CC BY) license (http://creativecommons.org/licenses/by/4.0/). 